\title{
Correction
}

\section{Correction: Sani et al., Selective Tuning for Contrast in Macaque Area V4}

For the article "Selective Tuning for Contrast in Macaque Area V4" by Ilaria Sani, Elisa Santandrea, Ashkan Golzar, Maria Concetta Morrone, and Leonardo Chelazzi, which appeared on pages 18583-18596 of the November 20, 2013 issue, the authors wish to point out that findings compatible with the notion that visual responses of some macaque V4 neurons are reduced for high versus low luminance contrast were also reported in a study by Bushnell and colleagues (2011). Those authors found that some V4 cells, which they termed "equiluminance cells", showed color-selective responses only under conditions of low-to-zero luminance contrast of the stimulus.

The full citation is listed below.

Bushnell BN, Harding PJ, Kosai Y, Bair W, Pasupathy A (2011) Equiluminance cells in visual cortical area v4. J Neurosci 31:1239812412. CrossRef Medline

DOI: 10.1523/JNEUROSCI.0154-14.2014 